Document downloaded from:

http://hdl.handle.net/10251/60346

This paper must be cited as:

Palmer, C.; Urwin, E.; Pinazo-Sanchez, J.; Sánchez Cid, F.; Pajkovska-Goceva, S.; Young, R. (2014). Reference Ontologies to Support the Development of New Product-Service Lifecycle Systems. En Advances in Production Management Systems: Innovative and Knowledge-Based. Springer Verlag. 642-649.

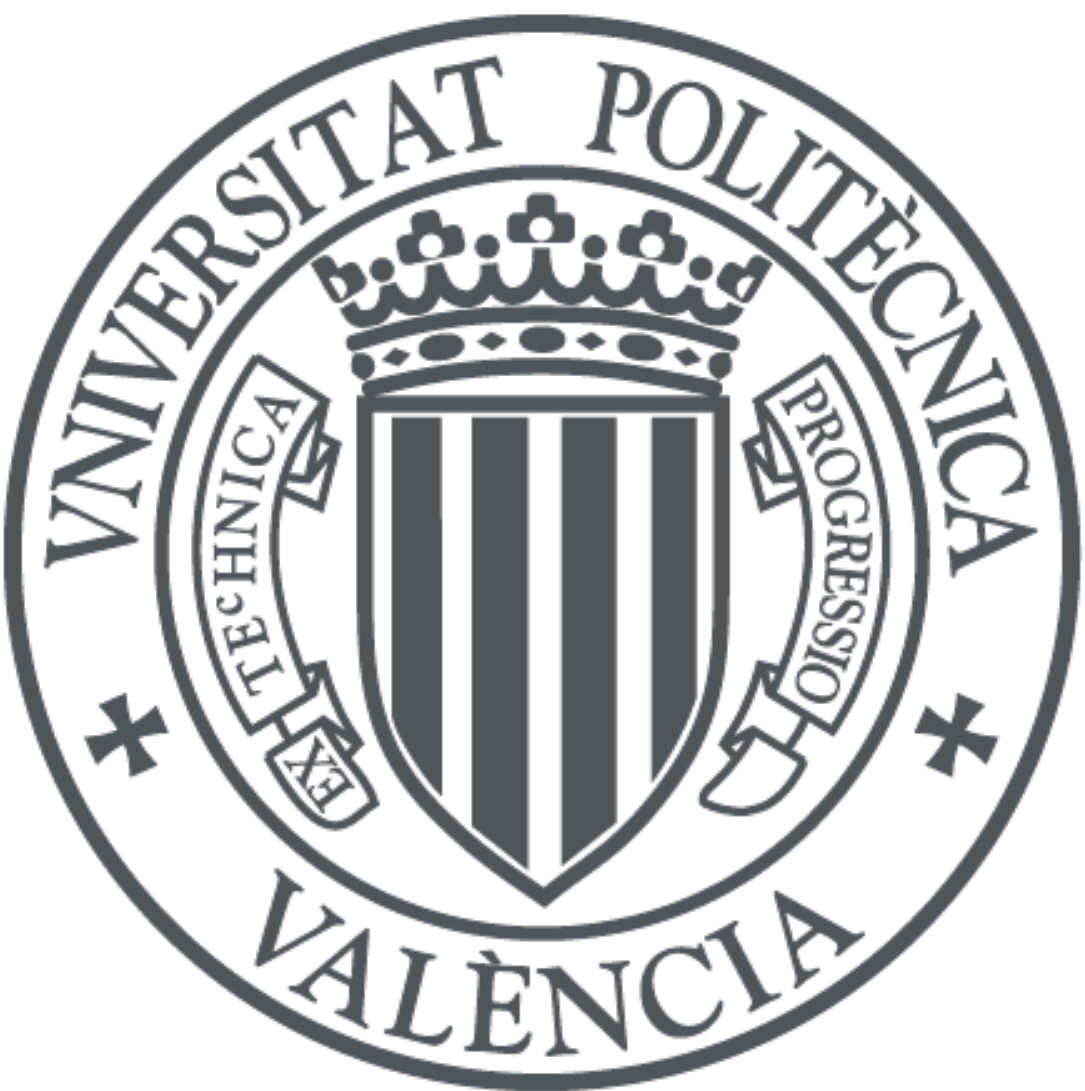

The final publication is available at

http://www.springer.com/gp/book/9783662447352?wt_mc=ThirdParty.SpringerLink.3.EPR65 3.About_eBook

Copyright Springer Verlag

Additional Information 


\title{
Reference Ontologies to Support the Development of New Product-Service Lifecycle Systems
}

\author{
Claire Palmer ${ }^{1}$, Esmond Neil Urwin ${ }^{1}$, Jose Miguel Pinazo-Sánchez ${ }^{2}$, Francisco \\ Sánchez $\mathrm{Cid}^{3}$, Sonja Pajkovska-Goceva ${ }^{4}$, Robert Ian Marr Young ${ }^{1}$ \\ ${ }^{1}$ Wolfson School of Mechanical and Manufacturing Engineering, Loughborough University, \\ Loughborough, Leicestershire, UK \\ \{c.palmer3, e.n.urwin, r.i.young\} @lboro.ac.uk \\ 2 ainia centro tecnológico, Parque tecnológico de Valencia, Avinguda de Benjamin Franklin, 5- \\ 11, 46980 Paterna, Valencia, Spain \\ \{jmpinazo\}@ainia.es \\ ${ }^{3}$ Instituto Tecnológico de Informática, Camino de Vera s/n, Edif. 8G, Acceso B, CP 46022, \\ Valencia, Spain \\ \{cid\}@iti.es \\ ${ }^{4}$ Fraunhofer Institute for Production Systems and Design Technology IPK, Pascalstraße 8-9, \\ 10587 Berlin, Germany \\ \{sonja.pajkovska-goceva\} @ipk.fraunhofer.de
}

\begin{abstract}
In competitive and time sensitive market places, organisations are tasked with providing Product Lifecycle Management (PLM) approaches to achieve and maintain competitive advantage, react to change and understand the balance of possible options when making decisions on complex multi-faceted problems, Global Production Networks (GPN) is one such domain in which this applies. When designing and configuring GPN to develop, manufacture and deliver product-service provision, information requirements that affect decision making become more complex. The application of reference ontologies to a domain and its related information requirements can enhance and accelerate the development of new product-service lifecycle systems with a view towards the seamless interchange of information or interoperability between systems and domains.
\end{abstract}

This paper presents (i) preliminary results for the capture and modelling of enduser information and (ii) an initial higher level reference core ontology for the development of reference ontologies to ameliorate product-service lifecycle management for GPN.

Keywords: product lifecycle management, global production networks, reference ontologies, interoperability, product service lifecycle systems.

\section{Introduction}

The nature of competition dictates rivalry and in the domain of manufacturing industry the act of competing for supremacy in the design, production and selling of products. The 21 st century information age is forcing manufacturers to act differently to compete

adfa, p. 1, 2011

(C) Springer-Verlag Berlin Heidelberg 2011 
successfully and find different ways in which to not only source and manufacture products but also configure and then sell them to customers.

The servitisation of products i.e. 'the increased offering of fuller market packages or 'bundles' of customer focused combinations of goods, services, support, self-service and knowledge' [1] is proving to be an enticing form of selling products via services to customers. Whilst the benefits can be seemingly apparent and instant, the actuality is that there are many additional components that are necessary.

The challenge for manufacturing industry which is servitising products is, what is the most effective way to design, produce and sell a product together with it associated service components effectively, to form a Product-Service System (PSS)? At the heart of this is how to align and integrate a traditional product lifecycle viewpoint with a more modern service lifecycle to develop a Product-Service Lifecycle System (PSLS). Additional complexity is added to this approach when Global Production Networks (GPN) are to be configured and reconfigured and in the face of rapidly changing product-service requirements. By employing a GPN, organisations can adopt technology at a faster pace, lower costs and be more open to change [12]. But an important aspect must be considered carefully, that of information interoperability between suppliers, manufacturers and service provision mechanisms. This becomes paramount when configuring sizeable and diverse GPN across potentially large geographical areas and between widely varying domains and contexts. It can introduce a wide and varied range of risks and perturbations from diverse system processes and capabilities, to different legislation and laws. One such method that can mitigate these risks to information interoperability is the use and application of ontological reference models.

What can be derived from this is that organisations are tasked with providing product lifecycle management (PLM) approaches and solutions to enable the sharing, use and reuse of information and knowledge, the main objective of this being to achieve and maintain competitive advantage for their Product-Service Systems [3]. They must be able to react to change and understand the balance of possible options when making decisions on complex multi-faceted problems, GPN is one such domain in which this applies.

Two interesting formal reference ontologies for interoperability have been put forward, those of the Interoperable Manufacturing Knowledge Systems (IMKS) project [4] and the Manufacturing Core Ontology (MCO) [5]. These concern the design, manufacturing and assembly of a product, as such they do not include or allow for PSLS nor GPN. What is highlighted by this is the need to develop formal reference ontologies to help develop, implement and ameliorate interoperability within PSLS when employing a GPN.

The premise of this paper is to put forward the notion that the application of formal reference ontologies to a domain and its related information requirements so as to enhance and accelerate the development of new PSLS with a view towards the seamless interchange of information or interoperability between systems and domains. This approach is being developed as part of the research being undertaken in the EU FP7 FLEXINET project. 
This paper is structured as follows. Section 2 discusses the FLEXINET project and its purpose. Section 3 sets out the methodological approach and development of reference ontologies for product-service lifecycle systems. Section 4 draws the paper to a close with conclusions and further work.

\section{The FLEXINET View}

FLEXINET aims to support decision-making in the early design of global production network configurations based on the implementation of new complex technologies. FLEXINET will apply advanced solution techniques to the provision of a set of Intelligent Production Network Configuration Services that can support the design of high quality manufacturing networks, understanding the costs and risks involved in network re-configuration, and then mitigating the impact of system incompatibilities as networks change over time. These are fundamental requirements for high quality decisionmaking in the early design of intelligent manufacturing system networks. These innovative concepts will enable a fast and efficient response to market variations and be easily adaptable across industrial sectors. The FLEXINET concept is illustrated in Figure 1 .

FLEXINET takes the view that new manufacturing business modelling methods are needed that can model business cases and identify the critical network relations that underlie the business operation. Such methods and models are essential to the ability to define both the production network knowledge that must be captured and the queries that must be made if new business configuration possibilities are to be evaluated. Product servitisation adds to the complexity of this problem as the relationships between product lifecycles and service lifecycles also need to be understood and their impact on production system networks specified within the resulting business models.

The main aims of the FLEXINET ontological research are the following, (i) document key semantic concepts, knowledge constraints and inter-relationships in the context of globalised production networks, (ii) structure and formally model concepts, relationships, constraints and related facts to provide an underpinning environment against which specific network configuration designs can be evaluated and (iii) develop methods for ontology querying from which to evaluate the compliance of potential production network configurations from both OEM and SME perspectives. 


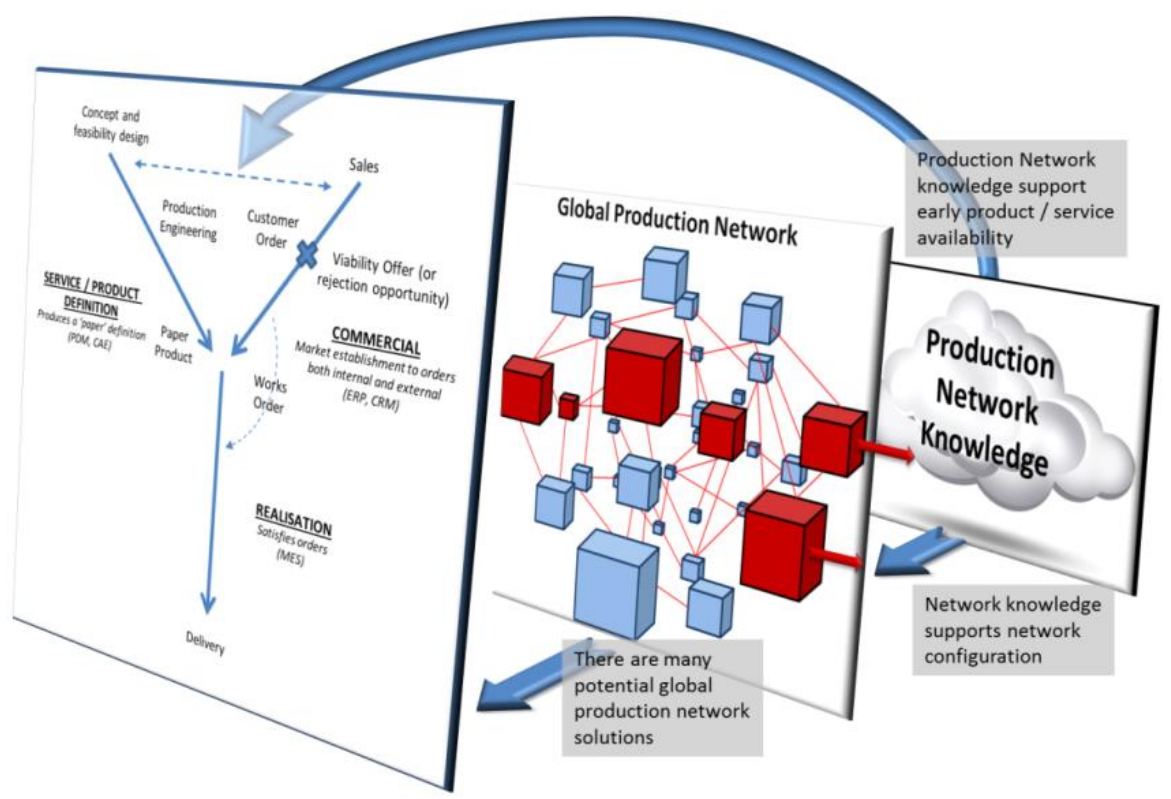

Figure 1. The FLEXINET Concept: Intelligent Production Network Configuration Services.

\section{A Reference Ontology for Product-Service Lifecycle Systems}

The starting point for the development of the FLEXINET formal reference ontology for product-service lifecycle systems has been three industrial case studies which have provided a solid base for the elicitation and capture of information and knowledge. In addition to this, the work from the Interoperable Manufacturing Knowledge Systems (IMKS) project, the Manufacturing Service Ecosystem (MSEE) project and the Manufacturing Information ontological model set out by Hastilow [6] is being assessed for applicability to the GPN and PSLS domains.

The FLEXINET approach focuses on the intelligent configuration of a network of products or product-service systems, to support interoperability between systems and domains the approach utilises a core foundation ontology. To enable ease of construction and to facilitate re-use across domains the FLEXINET ontology is organised into five levels, as illustrated in Figure 2. Each level inherits concepts from and provides additional concepts to the level above, the ontology becoming more domain specific with each level. Five levels are needed to specialise the concepts from the foundation to the specific domains. Figure 2 shows example domains at each level, the scope of FLEXINET being indicated in white. 


\begin{tabular}{l}
\hline Level 0 \\
\hline Level 1 \\
\hline Level 2 \\
\hline Level 3 \\
\hline
\end{tabular}

Figure 2. The FLEXINET ontology levels

Level 0 Core consists of foundation concepts applicable to all domains, having nothing to do directly with Product-Service Lifecycle Systems. The foundation concepts include time, events, aggregation and lists and are derived from the Highfleet Upper Level Ontology (ULO) [7]. Level 1 contains the few key concepts necessary to model any system. A system transforms inputs into outputs and is defined as "a combination of interacting elements organized to achieve one or more stated purposes" [8]. Level 2 uses Banathy's classification [9] to specialise systems into "Natural Systems" and "Designed Systems". Natural systems are living systems of all kinds, the solar system and the Universe. Designed systems are man-made creations, including fabricated physical systems, conceptual knowledge and purposeful creations. FLEXINET will provide decision support for product lifecycle management and, as this requires human input (i.e. input from a living system), the scope of FLEXINET covers purposeful creations and overlaps into natural systems.

Level 3 further differentiates designed systems, FLEXINET being concerned with Manufacturing Business Systems which are specialised within Level 4. At this level FLEXINET considers Product-Service Lifecycle Systems, implemented as Global Production Networks. The lifecycle phases are denoted as design, produce, operate and end of life (including disposal, recycling and remanufacturing). The focus of FLEXINET is how to design a GPN to produce and operate a product-service. The main area FLEXINET considers within the Product-Service Lifecycle is "Produce" (producing the product) but the scope also overlaps into "Design" (of the network) and "Operate" as the operation of the product and the service needs to be considered. Level 5 applies Level 4 to case studies creating enterprise specific domains.

Figure 3 sets out the level 1 ontology. It applies the Unified Modelling Language (UML) [10] technique to describe the details about the concepts and relations necessary to specify a system. This ontology level utilises the concept TimeSpan (inherited from 
Level 0) and contains two parent concepts: Basic and Role. A TimeSpan includes the first and last instants of a date and all the instances in between [7]. A Basic concept [11] is independent of the system or context, its definition does not depend on another concept and an instance of a Basic always retains its identity as such. Examples of Basic are information and material. A Basic can be comprised of Basics, e.g. "bottled water" is comprised of the materials "bottle", "cap" and "mineral water". A System is subtype of Basic and provides a context for the Roles it contains (shown via the "depends on" relation and the composition filled diamond in the figure).

The definition of a Role depends on a context, an instance of a Role cannot exist without a context and the playsRole relation is transitory. For example, a person Joe has a Role as a lecturer (context "university") and changes Role to a consultant (context "enterprise"), whereas the Basic "bottle" is always a "bottle". It can be seen that a lecturer Role cannot exist without the university context, if the university closes the lecturer role ceases to exist. Roles may be comprised of Roles (e.g. a lecturer Role may be comprised of administration, teaching and staff Roles).

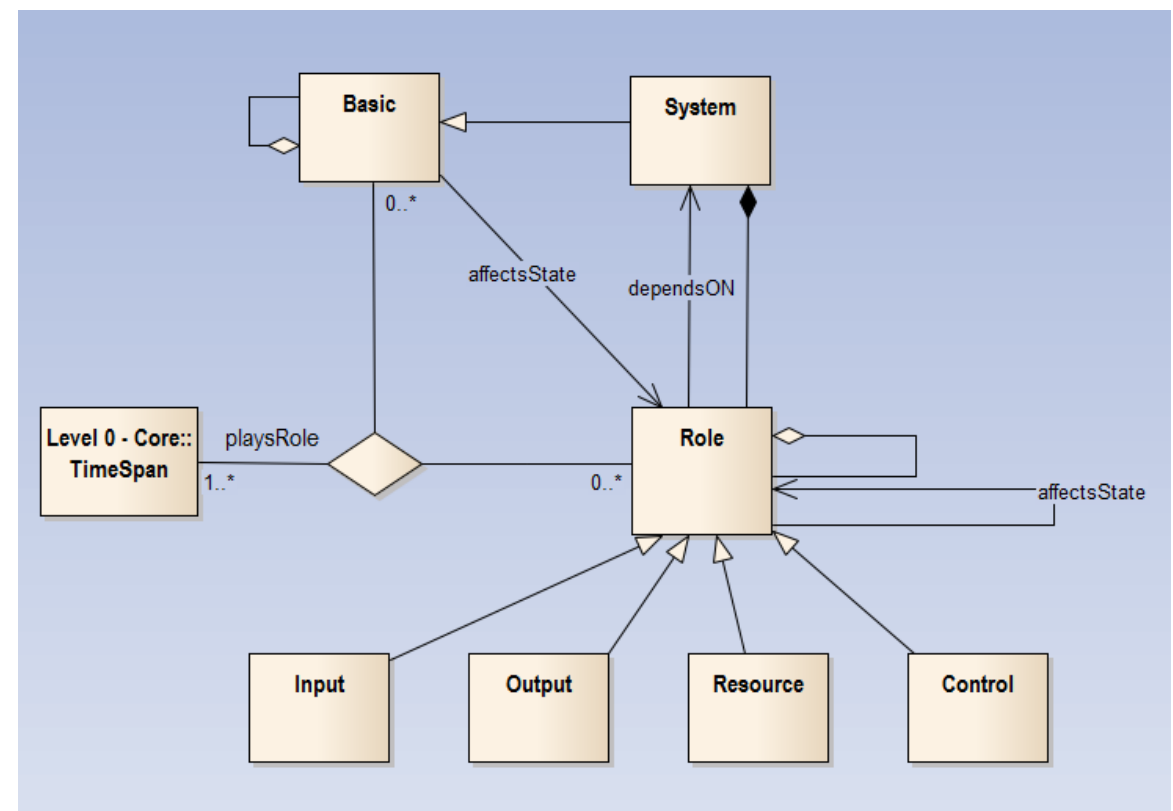

Figure 3: FLEXINET Level 1 Systems Ontology

A Basic plays a Role for certain TimeSpans, modelled in the ternary relation "playsRole". For example in the context of a manufacturing organization system, the Basic "bottled water" can play the Role of a Product during the TimeSpan of the system. Within a University a person could play the Role of a lecturer for a TimeSpan of five years, become unemployed and then play the Role of a lecturer again for a further TimeSpan.

A Basic can play more than one Role at the same time (e.g. a person could be a lecturer and a parent). A Role can be played by more than one Basic, e.g. the role of a 
laundry would require a washer and a drier. There is no requirement for a Basic to play a Role (shown by the $0 .{ }^{*}$ multiplicity next to the Role concept in the figure). Role and Basic concepts exist separately and have separate identities. There is also no requirement for a Role to be played by a Basic, enabling empty Roles to be modelled (e.g. if a person Joe left his Role as a lecturer the Role would still exist as a lecturer vacancy).

A Basic may affect the state of a role, e.g. the size of a Basic "bottled water" playing the Role of a product could influence the dimensions required for a packing resource Role. Additionally a Role may affect the state of a Role, e.g. within the lecturer Role more duties allotted to the administration Role would cause duties to be removed from the teaching Role).

The four key Roles which describe a system are input, output, resource and control. An input represents what is brought into and is transformed or consumed by the system to produce outputs. An output represents what is brought out from or is produced by the system. A resource is used by or supports the execution of the system. A control is a condition required to produce correct system output $[12,139]$.

\section{Conclusions and Furtherwork}

This paper has illustrated a lightweight reference ontology for Product-Service Lifecycle Systems comprised of a higher level core or foundation ontology that can act as a base for the generation and building of formal reference ontologies, not only for global production networks but other domains that are related and have potential for interoperation. The research approach and ideas put forward are actively being developed against a set of formalised FLEXINET industrial end user requirements and needs. Moreover the FLEXINET ontological research objective of 'define reference ontologies from which to base the flexible re-configuration of globalised production networks' is helping guide and focus the approach.

Further development of the reference ontology is needed against the FLEXINET industrial end user requirements, together with the IMKS [4], MSEE and MCO [6] ontologies to expand, refine and advance the research. When this has been achieved it will then be necessary to test the FLEXINET reference ontology utilising industrial information and knowledge to verify the approach and validate it against the end user requirements, this will provide valuable feedback to further enhance the approach.

\section{Acknowledgements}

We wish to acknowledge the FLEXINET consortium and especially the financial support from the European Union Seventh Framework Programme FP7-2013-NMP-ICTFOF (RTD) under grant agreement no 688627. 


\section{References}

1. Vandermerwe, S. and Rada, J., 1988. Servitization of business: adding value by adding services. European Management Journal, vol. 6 no. 4, pp. 314-324.

2. Coe, N.M., Dicken, P., Hess, M., 2007. Global production networks: realizing the potential. Economic Geography Research Group, Working Paper Series No. 05.07.

3. Young, R.I.M., Gunendran, A.G., Chungoora, N., Harding, J.A., Case, K., 2009. Enabling interoperable manufacturing knowledge sharing in PLM. Proceedings of the Sixth International Conference on Product Life Cycle Management PLM09, University of Bath, Bath, UK, July 6-8, Switzerland, Inderscience Enterprises Ltd., pp.130-138.

4. Chungoora, N., Young, R.I.M., 2011. The configuration of design and manufacture knowledge models from a heavyweight ontological foundation. International Journal of Production Research, vol. 49 no. 15, pp. 4701 - 4725.

5. Chungoora, N., Cutting-Decelle, A-F., Young, R.I.M., Gunendran, G., Usman, Z., Harding, J.A., Case, K., 2013a. Towards the ontology-based consolidation of production-centric standards, International Journal of Production Research, vol. 51 no. 2, pp. 327-345.

6. Hastilow, N., 2013. An Ontological Approach to Manufacturing Systems Interoperability in Dynamic Change Environments. PhD Thesis. School of Mechanical and Manufacturing Engineering, Loughborough University, UK.

7. Highfleet Ontology Library Reference, 2014. Baltimore, MA: HIGHFLEET Inc.

8. International Standards Society, 2008. ISO/IEC 15288:2008 Systems and Software Engineering - System lifecycle processes. Genève: ISO.

9. Banathy, B. H., 1992. A systems view of education: Concepts and principles for effective practice. Educational Technology.

10. OMG, $2012 \mathrm{OMG}$ unified modeling language (OMG UML), superstructure and infrastructure version 2.4.1 [online]. Available from: http://www.omg.org/spec/UML/2.4.1/ [Accessed 9 May 2014].

11. Mizoguchi, R., Kozaki, K., \& Kitamura, Y. (2012, September). Ontological analyses of roles. In Computer Science and Information Systems (FedCSIS), 2012 Federated Conference on (pp. 489-496). IEEE.

12. PUBs, F. (1993). Integration definition for function modelling (IDEF0). Federal information processing standards publication, 183.

13. POP* Revised framework Work package - A1.8 (2006). Athena European integrated project no. 507849 public deliverable. 